\title{
ORAL MANIFESTATIONS CONSISTENT WITH CHRONIC KIDNEY DISEASE
}

\author{
Anna Nenova-Nogalcheva \\ Department of Oral and Maxillofacial Surgery, Faculty of Dental Medicine, \\ Medical University of Varna
}

\begin{abstract}
Chronic kidney disease (CKD) is a condition defined by the progressive loss of renal function and damaging, in the course of months or years. Its rising incidence on a global scale compels doctors of dental medicine to be aware of the oral manifestations and symptoms affecting the soft and hard dental tissues, which are related to the underlying condition or its treatment. The objective of this review is to look into the oral changes affecting some of the patients with terminal kidney failure receiving chronic dialysis treatment.
\end{abstract}

Keywords: oral changes, chronic kidney disease, haemodialysis treatment

\section{INTRODUCTION}

Chronic kidney disease (CKD) is among chronic diseases most frequently leading to long-term and significant deterioration of the quality of life. It is a clinical and laboratory syndrome occurring as a result of the progressive loss of renal function and damaging over months and years. Typically, the glomerular filtration rate is reduced and the serum creatinine and urea levels are increased. The most common causes contributing to CKD are primarily: arterial hypertension, diabetes mellitus, chronic glomerulonephritis, chronic interstitial nephritis, arterial hypertension, and autoimmune conditions $(1,2,3)$.

According to data for 2012, about $8 \%$ of the human population (over 50 mil. people) are affected by CKD with an upward trend in almost all coun-

Address for correspondence:

Anna Nenova-Nogalcheva

Faculty of Dental Medicine,

Medical University of Varna

84 Tzar Osvoboditel Blvd,

9000 Varna, Bulgaria

e-mail:anenova@yahoo.com

Received: November 3, 2016

Accepted: November 9, 2016 tries $(4,5,6)$. The incidence of the disease in Bulgaria is nearly $10 \%$ (about 700,000 - 750,000 people). In 2015 , the total number of patients treated in dialysis centres across the country was 4,000 people. Of those, there are currently over 3,500 people receiving substitutive dialysis treatment. Forecasts show their numbers will continue to rise due to the constant rise in patients with Type 2 diabetes mellitus and hypertension $(7,8,9)$.

Patients with CKD are at high risk of developing oral complications related to their underlying condition or as a result of its treatment (10). A number of studies have found that the length of dialysis treatment influences the development of oral changes $(11,12,13)$. In up to $90 \%$ of such patients, manifestations and symptoms affecting the soft and hard dental tissues may occur, forcing dental treatment to adapt to the underlying condition and the main general manifestations of the disease, which requires dental specialists to have an in-depth knowledge.

The possible oral and facial issues in patients with CKD are:

$\diamond$ gingival hyperplasia

$\diamond$ generalized gingivitis catarrhalis

$\diamond$ inflammatory changes in oral mucosa 
$\diamond$ paleness of oral mucosa as a result of anaemic syndrome

$\diamond$ xerostomia

$\diamond$ impeded/altered taste sensation

$\diamond$ uremic fetor

$\diamond$ uremic glossitis

$\diamond$ uremic stomatitis

$\diamond$ individual tooth mobility

$\diamond$ heavy and irregular calculus builds up

$\diamond$ delayed tooth eruption

$\diamond$ enamel hypoplasia

$\diamond$ narrowing of the dental pulp chamber

$\diamond$ diminished prevalence of caries

$\diamond$ bone changes

\section{Halitosis and Uremic Fetor}

Halitosis may be a result of poor oral health, xerostomia or oral microorganisms metabolising urea (14). Uremic fetor is a well-recognised symptom of CKD patients. The reduced kidney function leads to higher levels of urea in the blood and the saliva, where it transforms to ammonia. The urea released in the mouth cavity becomes hydrolysed leading to the secretion of ammonia that is responsible for the bitter taste in the mouth (uremic fetor -foetor uraemicus) and the more alkaline the $\mathrm{pH}$ of the saliva. This typical uremic fetor is reported by $1 / 3$ (one third) of the patients in dialysis treatment (15).

Xerostomia - results from the limited liquid intake, side effects of drug therapy and the bad habit of breathing through the mouth. Continuous xerostomia is a predisposition to tooth caries and gingival inflammation, and later difficulties in speech and the act of chewing, loss of taste sensations, oral infections such as candidiasis and acute suppurative sialoadenitis $(16,17)$.

Altered (Impeded) Taste Sensation - caused by metabolic disorders, a systematic use of drugs, lowered number of taste buds and changes in the speed of saliva secretion (18).

Uremic Stomatitis is an oral complication of yet undefined aetiology that is usually seen in patients with end stage kidney diseases. It can manifest as white, red or grey lesions on the oral mucosa. It is thought that it may be due to the chemical trauma of the oral mucosa from the heightened levels of nitrogen compounds (16). The diagnosis is made by a combination of the typical clinical presentation with the histology result - inflammatory infiltrate with hyperplastic epithelia, which normally presents with abnormal keratinisation. $(19,20)$.

Enamel Hypoplasia is a common oral manifestation in patients with CKD. It is due to hypocalcaemia, poor vitamin D3 metabolism, metabolic acidosis, frequent intake of drugs affecting the ameloblast function. It manifests in $31 \%$ of primary (baby) teeth and affecting between $12 \%$ and $39 \%$ of permanent (adult) teeth. The clinical picture is linked to the reduced quantity of enamel as well as enamel defects manifesting in the shape of fissures, lines, dots and tooth discoloration in the yellowish - brown range. An altered teeth morphology is also observed as manifested in irregular incisive edges and tubercles (21).

\section{Tooth Anomalies}

In some CKD patients, narrowing of the dental pulp chamber is observed. It is assumed that this is due to the changes in calcium and phosphorus metabolism in patients with systemic kidney disease $(15,22)$. The exact reason for this dental alteration is unknown. Kidney transplant patients have a considerably narrower dental pulp chamber than patients on substitution treatment (16).

Tooth Mobility - possibly a result from kidney osteodystrophy, often seen in patients with kidney failure and as a result of secondary hyperparathyroidism $(21,23)$.

Gingival Hyperplasia - secondary to drug treatment, as a result of cyclosporines and/or calcium antagonists and is one of the most typical and common manifestations of kidney disease. It is a consequence of hyperplasia of the connective tissue and epithelia. The histology is typical - packed parallel collagen fibres with an increased number of fibroblasts and newly formed blood vessels. Acanthosis of the epithelium and epithelial in-growth in the connective tissue spreading deep within, may be observed.

Gingival hyperplasia can be seen around the front teeth (localised form) mainly, but can also be observed around all teeth (generalised form). Normally, the process begins from the interdental papilla, with the hyperplasia later expanding to the gingiva. This oral manifestation is present in 6 to $85 \%$ of 
patients on cyclosporine. Clinical presentation could become obvious as early as the first three months from the onset of the cyclosporine therapy. Children and youths are more susceptible to drug-induced gingival hyperplasia than adults (16). Nifedipine-induced hyperplasia is present in $10-83 \%$ of treated patients. Poor oral hygiene and tartar can also be a predisposition to gingival hyperplasia.

Earlier studies suggest that the oral hygiene of patients on haemodialysis is poorer than that of the general public as a whole (21). One probable reason is the chronic nature of the disease. Such patients are prone to overlooking preventive measures linked to other aspects of health (14). The increased deposit of tartar compared to healthy people is possibly connected to the high levels of urea and phosphates in the saliva, as well as the larger quantities of calcium carbonate they take (14). Poor oral hygiene and plaque development are risk factors for the onset of periodontal disease, which in turn is a potential cause for a prolonged systemic inflammation in this group of patients (14). Other authors have documented that the higher levels of urea in the saliva have an antibacterial effect, and that in that group of patients the incidents of dental caries are lower (24).

To summarise, it is assumed, that in patients with CKD, the compromised oral status and the increased accumulation of tartar are contributing factors to oral diseases (14).

Oral Mucosa Lesions - often occur secondary to drug therapy (for example diuretics beta-blockers, etc.) For instance, hairy leukoplakia may result from immunosuppression (16).

Some of the oral lesions in the spectrum, typical for CKD patients on HD are:

$\diamond$ oral erosions and ulcers

$\diamond$ oral lichen planus

$\diamond$ histopathology similar to Epstein - Barr virusassociated lesions - hairy leukoplakia

$\diamond$ white and erythematous patches

$\diamond$ uremic stomatitis

$\diamond$ geographic tongue and others Malignant Oral Lesions

Kaposi's sarcoma has been described in kidney transplant patients. There is data for the development squamous cell carcinoma in areas of cyclospo- rine-induced gingival hyperplasia. Continuous immunosuppressive treatment after kidney transplantation may predispose to the development of Kaposi's sarcoma.

Infections of the Oral Mucosa (Infections of the Mouth Cavity)

CKD patients on substitutive treatment, due to being immunosuppressed, can develop angular cheilitis, gingivitis or chronic atrophic candidiasis (16). Nearly $100 \%$ of those have a periodontal disease. Causes are not completely clear but it is suggested that systemic treatment with anticoagulants in patients on $\mathrm{HD}$, may be a predisposing factor for spontaneous bleeding from the gums that facilitates bacterial colonisation in the oral cavity (24). The secondary hyperparathyroidism is another possible reason for the periodontal diseases in patients with terminal kidney failure (24). Periodontitis is a potential source of bacteraemia, particularly in immuno-compromised patients $(24,17)$.

Bone Lesions ("Bone Disease") - varying from conditions affecting mineralisation to conditions significantly increasing bone metabolism (hyperparathyroidism). Bone changes in the maxillofacial area in chronic kidney failure are secondary to renal osteodystrophy. It causes reduced generation of active vitamin $\mathrm{D}$, leading in turn to lower serum levels of calcium and higher levels of parathormone (PTH) (25).

Renal osteodystrophy presents with a number of X-ray imaging changes in the upper and lower jaws. There is data for reduction or loss of cortical bone of the mandibular angle and around the maxillary sinuses (obscuration of the X-ray contrast lines depicting the outlines of the maxillary sinus), foramen mentale, the mandibular canal.

Bibliographical data (16) shows that hyperparathyroidism-based bone orofacial characteristics of renal osteodystrophy are:

$\diamond$ bone demineralisation

$\diamond$ reduction of trabeculae spaces

$\diamond$ thinning of cortical bone

$\diamond$ matt glass phenomenon in bone (trabeculae arrangement with matt-glass-like appearance)

$\diamond$ bone lesions with reduced X-ray density

$\diamond$ metastatic soft-tissue calcifications 
$\diamond$ osteolytic lesions

$\diamond$ jaw fracture (spontaneous or during dental treatment)

$\diamond$ abnormal post extraction bone modelling

In some cases, in patients on prolonged haemodialysis significant expansion of the jaw bones' size may be observed (macrognathia), leading to facial deformities $(24,26,27)$.

Bone demineralisation may lead to fast bone destruction.

Orofacial characteristics of the renal osteodystrophy affecting teeth and the periodontium are:

$\diamond$ enamel hypoplasia

$\diamond$ lamina dura loss (full or partial loss of the lamina dura)

$\diamond$ expansion of the periodontal ligament

$\diamond$ severe periodontal destruction

$\diamond$ tooth mobility

$\diamond$ pulp calcification (pulp changes)

$\diamond$ narrowing of the dental pulp chamber

\section{CONCLUSION}

There is a proven high incidence of oral pathology in patients with end stage CKD receiving chronic dialysis treatment. This necessitates a comprehensive discussion of the problem and requires and interdisciplinary team of a general practitioner, a specialist nephrologist and a dental physician. Dental medical doctors must be able to expect, identify and treat adequately any changes occurring in the maxilla-facial area in this group of patients.

\section{REFERENCES}

1. Davey RX. Chronic kidney disease and automatic reporting of estimated glomerular filtration rate. Med J Aust. 2006;184(1):42-43.

2. KDOQI, Kidney Disease Outcomes Quality Initiative, Clinical Practice Guidelinne for chronic kidney disease: evaluation, classification and stratification. Am J Kidney Dis.2002; 39, S1-S266.

3. Levey AS, de Jong PE, Coresh J et al. The definition, classification and prognosis of chronic kidney disease: a KDIGO Controversies Conference report. Kidney Int. 2011;80(1):17-28.

4. Corrao AM, Lisi G, Di Pasqua G, et al. Serum cystatin $\mathrm{C}$ as a reliable marker of changes in glomer- ular filtration rate in children with urinary tract malformations. J Urol. 2006;175(1):303-309.

5. Levin A, Hemmelgarn B, Culleton B, et al. Guidelines for the management of chronic kidney disease. CMAJ. 2008; 179(11): 1154-1162.

6. Stevens LA, Levey AS. Chronic kidney disease in the elderly--how to assess risk. N Engl J Med. 2005;352(20):2122-2124.

7. Bauer C, Melamed ML, Hostetter TH. Staging of chronic kidney disease: time for a course correction. J Am Soc Nephrol. 2008 ;19(5):844-846.

8. Mathew T, Johnson D, Jones G. Chronic kidney disease and automatic reporting of estimated glomerular filtration rate: revised recommendations. Med J Aust. 2007; 459-463.

9. McAlister FA, Ezekowitz J, Tonelli M, at al. Renal insufficiency and heart failure: prognostic and therapeutic implications from a prospective cohort study. Circulation. 2004;109(8):1004-1009.

10. Chi AC, Neville BW, Krayer JW et al. Oral manifestations of systemic disease. Am Fam Physician. 2010 ;82(11):1381-1388.

11. Dencheva M, Kisselova A. Prolonged hemodialysis treatment and the impact on oral health. J ., Problems of dentistry, 2009, Volume XXXV, part II, 5965. (Денчева М, Киселова А. Продължително хемодиализно лечение и влиянието върху оралното здраве.С.,Проблеми на денталната медицина, 2009, том XXXV, част II,59-65.)

12. Block GA, Martin KJ, de Francisco AL et al. Cinacalcet for secondary hyperparathyroidism in patients receiving hemodialysis. N Engl J Med. 2004;350(15):1516-1525.

13. Dencheva M, Krasteva A, Gueorgieva T, et al. Oral findings in patients with replaced renal function-a pilot study. J of IMAB. 2010; 16(4):54-57.

14. Valerevna E. Condition of the oral cavity in patients with end-stage chronic renal failure who are on hemodialysis treatment. ABSTRACT by VAK 2009 / 14.00.21, PhD Yashchuk (Валерьевна Е . Состояние полости рта у больных с терминальной стадией хронической почечной недостаточности, находящихся на диализной терапии тема диссертации и автореферата по BAК 2009/ 14.00.21, кандидат медицинских наук Ящук)

15. De Rossi SS, Glick M. Dental considerations for the patient with renal disease receiving hemodialysis. J Am Dent Assoc. 1996; 127(2):211-219. 
16. Asaumi J, Aiga H, Hisatomi M, et al. Advanced imaging in renal osteodystrophy of the oral and maxillofacial region. Dentomaxillofacial Radiology 2001;30(1):59-62.

17. Triantafillidou K, Zouloumis L, Karakinaris G, et al. Brown tumors of the jaws associated with primary or secondary hyperparathyroidism. A clinical study and review of the literature. Am J Otolaryngol. 2006 ;27(4):281-286.

18. Ganibegović $M$. Dental radiographic changes in chronic renal disease. Med Arh. 2000;54(2):115-118.

19. Lima RB, Benini V, Sens YA. Gingival overgrowth in renal transplant recipients: a study concerning prevalence, severity, periodontal, and predisposing factors. Transplant Proc.2008; 40(5):1425-1428.

20. Vigneswaran N. Oral and maxillofacial pathology case of the month. Renal-osteodystrophy induced macrognathia. Texas dental journal 2001; 118(7):570-1, 582-583.

21. Tomov G, Djerassi R, Benyozef D. System and oral manifestations in patients with chronic renal failure relevant to dentistry. Dentamedika, 2015; 11, 8-9. (Томов Г, Джераси Р, Бенйозеф Д. Системни и орални изяви при пациенти с хронична бъбречна недостатъчност от значение за денталната медицина. Дентамедика, 2015; брой 11, 8-9.)

22. Tzamaloukas AH. Diagnosis and management of bone disorders in chronic renal failure and dialyzed patients. Med Clin North Am. 1990 ;74(4):961-974.

23. Marti Alamo S, Gavalda Esteve C, Sarrión Pérez MG. Dental considerations for the patient with renal disease. J Clin Exp Dent.2011; 3(2):e112-e119.

24. Dong BJ. Cinacalcet: An oral calcimimetic agent for the management of hyperparathyroidism. Clin Ther. 2005 ;27(11):1725-1751.

25. Souza CM, Braosi A, Luczyszyn S, et al. Oral health in Brazilian patients with chronic renal disease. Rev Méd Chile 2008; 136: 741-746.

26. Ferguson CA, Whyman RA. Dental management of people with renal disease and renal transplants. N Z Dent J. 1998 ;94(417):125-130.

27. Sobrado MJS, Tomás CI, Loureiro A et al. Oral health status in patients with moderate-severe and terminal renal failure. Med Oral Patol Oral Cir Bucal. 2007 ;12(4):E305-10. 